\title{
Cirugía cardíaca con videotoracoscopía: nuevos desafíos para el anestesiólogo
}

\author{
Dominella FG. ${ }^{1}$, Longo S. ${ }^{1}$, Masco LP. ${ }^{1}$ \\ 1 Hospital Privado de Córdoba, Córdoba, Argentina.
}

Introducción: La cirugía cardiaca mínimamente invasiva se impone como el futuro en la cirugía cardiovascular. Dentro de este grupo se destaca la cirugía cardiaca por videotoracoscopia, que presenta múltiples ventajas con respecto al abordaje tradicional. Esta técnica supone cambios y coloca al anestesiólogo en un rol activo: realizamos bloqueo de los erectores de la espina (ESP) para lograr adecuada analgesia post operatoria. Se requiere intubación selectiva con tubo de doble lumen, la canulación venosa se realiza mediante control ecocardiográfico transesofágico.

Métodos: Se analizaron 6 casos de cirugía cardíaca por videotoracoscopía.

Se incluye en el presente trabajo pacientes de 18 a 99 años, ASA I a IV, de ambos sexos cuyo procedimiento quirúrgico se lleve a cabo mediante video toracoscopía.

Se registra para cada paciente edad, sexo, clasificación ASA, procedimiento realizado, tiempo de CEC, tiempo trascurrido a la extubación, complicaciones, dolor postoperatorio, estadía en UTI y tiempo hasta el alta definitiva.

Resultados: La población incluyo cuatro hombres y dos mujeres (media de edad de hombres 62 años y de mujeres 68) Los pacientes presentaban status de ASA III o IV. Este abordaje resulto en mayores tiempos de CEC. Sin embargo, permitió lograr extubación temprana (dentro de las $2 \mathrm{~h}$ ). Los pacientes presentaron medianas de dolor medidas por EVN más bajos que en el abordaje tradicional. Además, los pacientes permanecieron menor cantidad de días en terapia intensiva.

Conclusión: La cirugía cardiovascular mínimamente invasiva coloca al anestesiólogo en un rol activo, debiendo realizar múltiples procedimientos invasivos. Esta técnica permite lograr un mayor confort postoperatorio para el paciente y permite disminuir las complicaciones postoperatorias.

https://doi.org/10.25237/congresoclasa2019.49 